andorrana, en el seu medi habitual, l'escola. Les eines utilitzades foren un inventari de dades sociobiogràfiques i el fitxer escolar de l'assesoria pedagògica. Per a l'obtenció de les dades sociolingüístiques: el test C.G.M. del Ministeri d'Educació Nacional francès, l'adaptació catalana de Gentil Puig i l'adap. tació a l'espanyol feta per nosaltres.

El segon comprèn les eines psicosocials. L'instrument fonamental per a obtenir les dades de la mateixa població ha estat l'ISAE-80, qüestionari psicosociolingüistic de Pere Notó i Magí Panyella.

El primer objectiu que ens imposàrem fou la construcció d'un banc de dades generals amb els resultats obtinguts de la recerca, codificats i programats en ordenador, que permet la realització de futurs treballs d'investigació. Pot ser, en aquest sentit, una eina útil per a fer l'avaluació del Pla d'Andorranització promogut pel M.I. Consell General a les escoles.

Un segon objectiu ha estat la verificaciô de les nostres hipòtesis que descrivim a continuació:

1. Hipòtesi: Existeix una correlació entre el coneixement oral $i / o$ escrit de la llengua catalana per part dels andorrans, i llur grau de consciència d'Identitat Social Andorrana.

2. Hipòtesi: El millor coneixement de la llengua catalana oral $\mathrm{i} / \mathrm{o}$ escrita, reverteix en el millor coneixement de qualsevulga de les altres llengües que es parlen i s'ensenyen a Andorra, és a dir, el francès i l'espanyol.

Conclusions i Lectura: Es verificaren les hipòtesis de forma general i completa. Igualment, ha quedat realitzat un banc de dades propietat de l'Institut d'Estudis Andorrans, que podrà acomplir les finalitats previstes.

\section{ERGONOMIA DE}

\section{L'APRENENTATGE MOTOR: UN ENFOCAMENT METODOLÒGIC}

\section{Joan Riera i Riera}

\section{Director: Ramon Bayés Sopena \\ Ponent: Ramon Companys Pascual}

Després de valorar la importància de l'estudi de l'aprenentatge de les destreses humanes, especialment en els àmbits laborals, de l'esport i el lleure, es revisen els principals models teòrics que s'utilitzen per a explicar l'aprenentatge. Aquests models poden agrupar-se en models físics, biològics, psicològics i sociològics, en relació a la disciplina que consideren més rellevant. S'observa que tots aquests models son organocèntrics, lineals $i$ estàtics, i es troba a faltar un model integrador.

Conseqüentment, la metodologia emprada en la investigació sol centrar-sé en l'anàlisi de les reaccions terminals de l'organisme o el seu rendiment, en lloc de fixar-se en l'evolució de les interaccions entre l'organisme i els objectes d'estímul, dins d'una perspectiva de camp multifactorial.

Per superar aquestes deficiències se suggereix la conveniència de disposar d'un model ergonòmic, multidisciplinari, que permeti conceptualitzar adequadament les interaccions humanes, en el marc teòric desenvolupat per Emilio Ribes a partir dels conceptes lògics descriptius formulats per J.R. Kantor. Des del punt de vista de la psicologia interconductual, l'aprenentatge motor es defineix com el procés pel qual s'estableixen un tipus d'interaccions, on les característiques motores de les accions de l'organisme estan relacionades amb l'ambient. Igualment, un enfocament interconductual ha d'analitzar l'evolució de les interaccions motores, sense oblidar els restants elements del camp psico. lògic individual que possibiliten, faciliten o dificulten el seu establiment.

El replantejament de l'aprenentatge mo- 
tor obliga a modificar la metodologia de recerca en aquest camp i fa necessari el registre continuat i directe de variables biomecàniques, fisiològiques, ambientals i del rendiment durant tot el procés d'adquisició. Per tal d'aconseguir-ho, s'han dissenyat i construiit diferents transductors per poder introduir simultaniàment en els canals d'un polí. graf, els paràmetres del moviment, ambientals i del rendiment, conjuntament amb els fisiològics.

Amb aquest instrument s'han analitzat els processos d'aprenentatge, retenció, transfe- rència $\mathrm{i}$ els efectes d'una situació opressora, en dues destreses: el llançament de dards a diana i el seguiment d'un circuit mitjançant un torn bimanual.

Els resultats obtinguts reflecteixen els avantatges d'un enfocament interconductual de l'aprenentatge motor i de l'instrument de registre multifactorial en possibilitar l'explicació dels canvis observats en el rendiment terminal i justificar la importància que pot tenir en l'estudi d'altres àrees d'interès psicològic.

\section{TESINAS}

\section{ESTUDIO COMPARATIVO DEL MIEDO EN ADOLESGEN- TES DE ZONA RURAL}

\section{Pilar Monreal Bosch}

\section{Director: Dra. Carmen Martínez González}

Dado que sobre el miedo en la adolescencia se han realizado pocos trabajos en comparación con el referido a las etapas infantiles (Pelechano, 1980) y adultas (Suedfeld, 1977), escogí dicho tema para mi Tesis de Licenciatura, con el fin de analizarlo de modo exhaustivo, dentro de mis posibilidades, recogiendo de los mismos adolescentes sus evocaciones o recuerdos de lo que les produce miedo o angustia.
A partir de las investigaciones llevadas a cabo por Rodríguez-TOME y BARIAUD (1975) en Francia, en zona rural y urbana, por SPELTiNi (1976) en Italia en medio urbano, inicié el trabajo de investigación sobre los miedos de los adolescentes en zona rural, siguiendo las pautas utilizadas con anterioridad por los ya citados, a fin de conseguir no hacer un estudio teórico sobre el miedo en la adolescencia, sino obtener una descripción de los mismos (objeto de miedo) relatados directamente y mediante cuestionarios abiertos.

El primer objetivo de nuestro trabajo es el de hacer un estudio descriptivo en dicha etapa evolutiva y analizar posibles diferencias significativas a nivel de sexo, edad y zona y así poder efectuar primeramente un estudio evolutivo del miedo en la adolescencia y, posteriormente, un estudio comparativo entre las diferentes zonas rurales españolas y a la vez compararlas en futuras investigaciones 